\title{
Correspondence
}

\section{How fast can babies breathe?}

Sir,

This is not a provisional entry for the Guinness Book of Records but an attempt to satisfy a longstanding and recently renewed curiosity.

As a house physician in Queen Elizabeth Hospital for Children in Hackney, I observed a respiratory rate of 180 /minute in a 3 -week-old preterm infant with an extensive bronchopneumonia which persisted for several hours, falling overnight to $120 /$ minute, followed by gradual return to more normal levels with recovery. Within the last month, a 5-week-old infant (admitted at 2 weeks with a campylobacter enteritis) gradually developed a variable laryngeal stridor, with occasional mild cyanotic episodes associated with rapid stridulous breathing, during one of which $I$ found the respiratory rate to be $172 /$ minute, a rate not subsequently equalled, although rates well over $100 /$ minute were recorded.

Have rates as high or higher been observed? The question is not entirely academic since I believe that some equipment designed to monitor respiration in infancy would not be capable of recording rates of this magnitude.

B McNicholl Department of Paediatrics, Regional Hospital, Galway, Ireland

\section{New immunofluorescent blood test for gluten sensitivity}

\section{Sir,}

We were surprised at the low incidence of anti-reticulin antibody (ARA) found by Unsworth ${ }^{1}$ in his patients with coeliac disease. These results are not consistent with those of others ${ }^{2}$ nor are they consistent with our results for children aged between 4 months and 12 years. During the last 4 years we have looked for the presence of ARA in many conditions, and have used indirect immunofluorescent assay. ${ }^{8}$

None of the 40 cases of the control group had circulating ARA, whereas out of 32 patients with gastroenterological diseases (such as giardiasis, introlerance to cows' milk protein, intractable diarrhoea), $4(12.5 \%)$ had positive results at the time of the biopsy; none had demonstrable coeliac disease.

Out of 48 patients with probable coeliac disease studied at the time of the first biopsy, $36(75 \%)$ were ARA positive. After one year on a gluten-free diet 21,
$(60 \%)$ of 35 cases were negative, but most of the remainder admitted they had frequently lapsed from the diet. Between 2 months and one year after gluten had been reintroduced to the diet, $15(68 \%)$ of the 22 patients were ARA positive.

It is our conviction that, although the presence of ARA cannot yet be considered to be the perfect screening test for detection and control of these patients, it is of considerable value.

Data now presented by Unsworth demonstrate that the presence of antibodies to gliadin is a non-specific test for coeliac disease. We think we shall only be able to draw firm conclusions if the same patients are studied in the three protocolar phases necessary to diagnose coeliac disease according to the criteria established by the European Society for Paediatric Gastroenterology and Nutrition. This was not the case in Unsworth's study nor was it so in our own.

\section{References}

1 Unsworth D J, Manuel P D, Walker-Smith J A, Campbell C A, Johnson G D, Holborow E J. New immunofluorescent blood test for gluten sensitivity. Arch Dis Child 1981; 56: 864-8.

2 Wright R. Coeliac disease and gastrointestinal allergy. In: Immunology of gastrointestinal and liver disease. London: Edward Arnold, 1977: 27-44.

3 Rizzetto M, Doniach D. Types of 'reticulin' antibodies detected in human sera by immunofluorescence. $J$ Clin Pathol 1973; 26: 841-51.

P Magalhães Ramalho and Estela Monteiro Pediatric Department, Gastroenterology Center, Sta Maria University Hospital, Av. Prof. Egas Moniz, 1.600 Lisbon, Portugal

\section{Hypernatraemic dehydration}

Sir,

In a recent paper the incidence of hypernatraemic dehydration (serum sodium $>150 \mathrm{mmol} / \mathrm{l}$ ) in patients admitted with gastroenteritis was shown to have fallen from $4.9 \%$ to $0.9 \%$ in a 4-year period at one hospital for the age group 0-2 years. During the latter part of 1980 it was felt that our hospital had witnessed an upturn in the incidence of this problem. It was found that the incidence of hypernatraemia was $4.2 \%$ (13) in 311 patients admitted with gastroenteritis under age 2 years. In 1970 the incidence was $5.8 \%(24)$ in 414 patients. The incidencer of hypertonic dehydration (serum osmolality $>300 \mathrm{mmol} / \mathrm{l}$ ) was $6.7 \%$ in 1970 and $9.6 \%$ in 1980 . Data on the age 
Table Age and racial origin of children with hypernatraemic and hypertonic dehydration

\begin{tabular}{|c|c|c|c|c|}
\hline \multirow[t]{3}{*}{ Type of dehydration } & \multicolumn{4}{|c|}{ Age (months) } \\
\hline & \multicolumn{2}{|l|}{$0-12$} & \multicolumn{2}{|l|}{$13-24$} \\
\hline & Asian & White & Asian & White \\
\hline \multirow{2}{*}{$\begin{array}{l}\text { Hypernatraemic } \\
\text { Hypertonic } \\
\text { (without hypernatraemia) }\end{array}$} & 7 & 3 & 3 & 0 \\
\hline & 4 & 3 & 1 & 0 \\
\hline
\end{tabular}

and racial origin of the patients in 1980 with hypernatraemia and hypertonic dehydration are shown in the Table.

Seven of the 8 children with hypertonic dehydration had serum sodium levels greater than $145 \mathrm{mmol} / \mathrm{l}$, a trend towards hypernatraemia. The type of milk given to the patient before admission was appropriate in every case and no particular pathogen played a major role in the disorder. These figures show that the incidence of hypernatraemia has not changed here during the last decade, and that education in the making-up of feeds and the use of appropriate oral fluids in the treatment of gastroenteritis is still needed.

\section{Reference}

1 Manuel P D, Walker-Smith J A. Decline of hypernatraemia as a problem in gastroenteritis. Arch Dis Child $1980 ; 55$ : 124-7.

M L SMITH

Leeds Road Hospital, Bradford,

West Yorkshire BD3 9LH

\section{Child health services after reorganisation}

Sir,

The annotation by Dr Wilson ${ }^{1}$ fills one with despair. So soon after the publication of the infant mortality statistics in different countries in the Court Report which showed how we have been so sadly overtaken, and at a time when our immunisation figures are so conspicuously bad, when childhood tuberculosis has recurred, family break up, smoking, violence, and accidents are all increasing, and schools are increasingly wreaking havoc on children's minds and personalities, how can you publish the sentence 'there will be little change in the child health services and no cause for concern.'?

The big advances in child health in this country occurred when it was in the hands of the people whom Dr Wilson calls 'epidemiologists' (my father was secretary of the Society of Medical Officers of Health in the 1930s, and was such a one) and with the onset of the disastrous and misnamed National Health Service, the relative rate of improvement declined. Dr Wilson is making the spurious assumption (which was also made at the onset of the National 'Health' Service) that the doctors who matter for health are those who see patients, and is perpetuating the longstanding confusion of health (prevention) and chronic care. I think that, if a doctor sees a patient, medicine has failed, and the correct sequence of importance of these aspects of medicine should be prevention, treatment, and chronic care. The one aspect of treatment which has really important preventive implications is obstetrics and neonatology, and our achievements in these have not been satisfactory until recently.

The lumping of these three categories of medicine (and 4 others which I have outlined elsewhere) together under the so-called National Health Service makes no sense, and has been very damaging, because the health (prevention) component has been given bottom priority instead of top. The prejudices of paediatricians and of your journal have also been for treatment and care; this is acceptable for a journal with your title but there is no evidence for her view that paediatrically trained people will do better than epidemiologists in forwarding child health; certainly much more health-orientated research is needed.

The sort of administrative juggling which Dr Wilson was discussing will have very little effect, good or bad, on the present state of child health, but anyone who can say that there is no cause for concern in our child health services is the wrong person to comment on them.

\section{Reference}

1 Wilson $\mathbf{J}$ A. Child health services after reorganisation. Arch Dis Child 1982; 57: 1-2.

J F SOOTHILL

Department of Immunology, Institute of Child Health, 30 Guilford Street, London WCIN $1 E H$

Dr Wilson comments:

Professor Soothill has taken the sentence 'there will be little change in the child health services and no cause for concern' out of context, from an annotation which discussed the effect on the organisation of the Child Health Services, of abolishing the post of specialist in community medicine (Child Health). There is of course, considerable cause for concern about the state of our children's health. In some districts I am also concerned about the organisation of their services for children and no doubt it would have been wiser to use the phrase "less cause for concern'. I have no doubt that the effectiveness of the present services would be greatly improved if the clinical staff were appropriately trained.

I do not dispute that an epidemiologist may have an important role to play in ensuring healthier children but I reiterate that a doctor who has no clinical experience of child health and paediatric medicine is not equipped to organise the clinical child health services or to train the doctors who practise there.

Professor Soothill disputes this, stating that neither the title (see above) nor the annotation indicated the restricted context to which Dr Wilson now refers.

Editor 